\title{
Influence of fragmented QRS complex in patients with paroxysmal atrial fibrillation
}

\author{
Centurión OA ${ }^{1,2 *}$, Torales JM ${ }^{1,2}$, García $\mathrm{LB}^{1,2}$ and Scavenius $\mathrm{KE}^{2}$ \\ ${ }^{1}$ Department of Health Sciences Investigation, Sanatorio Metropolitano, Fernando de la Mora, Paraguay, South America \\ ${ }^{2}$ Department of Cardiology, Clinic Hospital, Asunción National University (UNA), San Lorenzo, Paraguay, South America
}

In routine practice and clinical studies, a low left ventricular ejection fraction is routinely utilized for risk stratification in patients with structural heart disease. Despite the lack of desirable positive predictive value for the risk of cardiovascular events, systolic dysfunction is still widely used in clinical practice [1-5]. On the other hand, in patients with stable coronary artery disease and in patients with acute MI, fragmented QRS complex (FQRS) was found to be a good predictor of cardiac events [6-8]. It has been suggested that FQRS is caused by slow and non-homogeneous depolarization associated to healed myocardial scar [9-11]. There was a statistically significant difference in mortality associated to the presence of FQRS in patients with acute coronary syndrome and myocardial necrosis [12-16]. The finding of FQRS on a conventional 12-lead electrocardiogram (ECG) is associated to depolarization abnormality which suggests conduction delay from inhomogeneous activation of the ventricles due to myocardial scar. Therefore, several entities associated with the presence of myocardial scar formation such as coronary artery disease, cardiomyopathies, heart failure, and congenital heart diseases influence the finding of FQRS.

FQRS is defined as the presence of an additional R wave ( $R$ ') or notching in the nadir of the $S$ wave, or the presence of more than $1 R^{\prime}$ in 2 contiguous leads, corresponding to a major coronary artery territory on the resting 12-lead ECG with filter range $0.16-100 \mathrm{~Hz}, \mathrm{AC}$ filter $60 \mathrm{~Hz}$, paper speed $25 \mathrm{~mm} / \mathrm{s}$ and $10 \mathrm{~mm} / \mathrm{mV}$ [12]. Fragmented wide QRS complex (FWQRS) were defined as various RSR patterns with or without a $\mathrm{Q}$ wave, with more than $2 \mathrm{R}$ waves (R') or more than 2 notches in the $\mathrm{R}$ wave, or more than 2 notches in the down-stroke or upstroke of the $S$ wave, in 2 contiguous leads corresponding to a major coronary artery territory [12]. Flowers et al. showed that the slurring and changes in the morphology of the QRS complex are more common among patients with prior myocardial infarction (MI) and among patients with either right or left ventricular (LV) enlargement. They named it high-frequency components to the presence of FQRS complexes [9]. Friedman et al suggested that persistent changes in Purkinje fibers and myocardial fibrosis may cause slow and inhomogeneous myocardial activation in the canine heart with induced myocardial infarction [10]. In addition, Gardner et al. suggested that FQRS complex in infarcted canine heart is caused by slow and inhomogeneous activation associated to healed myocardial scar rather than changes in trans-membrane resting or action potentials [11]. The presence of FQRS represents distortion of signal conduction and depolarization process within the ventricles which is related to myocardial scar/myocardial ischemia or myocardial fibrosis.

The initiation and perpetuation of a circus movement reentrant ventricular arrhythmia depend on the firing of a trigger event such as a premature ventricular complex in the presence of a vulnerable myocardial substrate. Myocardial scars from a previous infarction may provide the anatomic substrate for ventricular tachycardia in patients with coronary disease and impaired left ventricular function. In patients with LV dysfunction, there is no clear evidence that presence of FQRS could predict arrhythmic events [17-20]. On the other hand, there was a statistically significant difference in mortality associated to the presence of FQRS in patients with acute coronary syndrome and myocardial necrosis [14].

It seems reasonable to associate the structural changes of the ventricular myocardium with structural and/or functional alterations in the atrium causing atrial arrhythmias. It was demonstrated that the FQRS was as predictor of the occurrence of post-operative atrial fibrillation $(\mathrm{AF})$ in patients after coronary artery by-pass graft (CABG) surgery [21]. Indeed, Cetin $\mathrm{M}$ et al. studied 272 patients who underwent isolated CABG surgery in a prospective observational design [21]. They divided the patients into two groups, those with postoperative $\mathrm{AF}$, and those without AF. The occurrence of new-onset AF following $\mathrm{CABG}$ and the relationship with FQRS were investigated. The logistic regression analysis was used to determine independent predictors for postoperative AF. The sensitivity and specificity of study variables in predicting postoperative AF were also calculated. They found that postoperative AF occurred in 62 of 272 patients (22.8\%). Patients with postoperative AF were generally older $(\mathrm{p}<0.001)$ and female $(\mathrm{p}=0.006)$, with preexisting hypertension $(\mathrm{p}=0.008)$, lower hemoglobin levels $(\mathrm{p}=0.011)$, chronic obstructive lung disease $(\mathrm{p}=0.003)$, prolonged QRS time $(\mathrm{p}=0.004)$, and higher EURO score $(\mathrm{p}<0.001)$ compared to non-AF patients. Patients with postoperative AF showed lower left ventricular ejection fraction $(\mathrm{p}<0.001)$ and higher incidence of FQRS $(\mathrm{p}<0.001)$, but similar left atrial size. However, LA size was significantly enlarged in patients with FQRS ( $3.8 \pm 0.6$ vs. $4.1 \pm 0.5 \mathrm{~cm}, \mathrm{p}=0.002)$. New-onset postoperative AF was significantly related to the presence and number of FQRS. In the logistic regression analysis, the presence and number of FQRS (OR: 6.020, 95\% CI: 3.152-11.5 and OR: 1.522, 95\% CI: 1.282-1.807, both of, $\mathrm{p}<0.001$ ) were independent predictors of postoperative AF [21]. Sensitivity, specificity, positive, predictive value, negative predictive value and the diagnostic accuracy of the presence of FQRS on preoperative ECG to predict postoperative AF were $66 \%, 76 \%$,

${ }^{\star}$ Correspondence to: Centurión OA, Professor of Medicine, Asuncion National University (UNA), Department of Health Sciences Investigation, Sanatorio Metropolitano, Teniente Ettiene, Ruta Mariscal Estigarribia, Fernando de la Mora, Paraguay, South America, E-mail: osmarcenturion@hotmail.com

Received: August 01, 2018; Accepted: August 10, 2018; Published: August 13, 2018 
$45 \%, 88 \%$ and $74 \%$, respectively. Therefore, they concluded that newonset postoperative $\mathrm{AF}$ was independently related to the presence and number of FQRS in patients undergoing CABG surgery. In addition, FQRS on preoperative surface ECG had high predictive values for newonset postoperative AF [21].

In order to study the relationship between FQRS and paroxysmal AF, Temiz A et al. investigated prospectively a total of 301 patients without overt structural heart disease [22]. Their patients were divided into 2 groups according to the presence of FQRS. They utilized multivariate logistic regression analysis in order to assess the predictive value of FQRS for predicting paroxysmal AF. They observed that 103 patients had FQRS. Patients with FQRS were older $(53 \pm 16.8$ vs $45.3 \pm 17.2 \mathrm{p}<$ $0.001)$, with larger left atrium ( $33.2 \pm 5.9$ vs $30.1 \pm 5.9 \mathrm{~mm}, \mathrm{p}=0.001)$, with thicker inter-ventricular septum $(10.2 \pm 1.9$ vs $9.5 \pm 2.3 \mathrm{~mm}, \mathrm{p}=0.032)$, more diabetics ( 19.8 vs $10.6 \%, \mathrm{p}=0.029)$ and have more episodes of paroxysmal AF (22.3 vs $4.1 \%, \mathrm{p}<0.001)$ in comparison with patients without FQRS. They found that FQRS was an independent predictor of detecting paroxysmal AF (odds ratio, 9.69; 95\% confidence interval, 2.46-38.15, $\mathrm{p}=0.001)$. Therefore, they concluded that the presence of FQRS independently predicted paroxysmal AF episodes in Holter ambulatory ECG monitoring [22].

In conclusion, the presence of FQRS seems to be a useful marker to help decision making for extended rhythm monitoring and therapeutic management in certain patients to reduce the AF-related complications. Nevertheless, the association of FQRS and atrial fibrillation is scantly reported hence, further studies are needed to clarify the clinical implications of this finding.

\section{References}

1. Zipes DP, Camm AJ, Borggrefe M, Buxton AE, Chaitman B, et al. (2006) ACC/AHA/ ESC 2006 Guidelines for Management of Patients With Ventricular Arrhythmias and the Prevention of Sudden Cardiac Death: a report of the American College of Cardiology/ American Heart Association Task Force and the European Society of Cardiology Committee for Practice Guidelines (writing committee to develop Guidelines for Management of Patients With Ventricular Arrhythmias and the Prevention of Sudden Cardiac Death): developed in collaboration with the European Heart Rhythm Association and the Heart Rhythm Society. Circulation 114: e385-e484.

2. Prystowsky EN (2004) Primary prevention of sudden cardiac death: the time of your life. Circulation 109: 1073-1075. [Crossref]

3. Myerburg RJ, Castellanos A (2008) Cardiac arrest and sudden cardiac death In: Braunwald's Heart Disease: A Textbook of Cardiovascular Medicine(8/ed). Philadelphia, PA: WB Saunders, 2008:933-974.

4. Luqman N, Sung RJ, Wang CL, Kuo CT (2007) Myocardial ischemia and ventricular fibrillation: pathophysiology and clinical implications. Int J Cardiol 119: 283-290. [Crossref]

5. Huikuri HV, Castellanos A, Myerburg RJ (2001) Sudden death due to cardiac arrhythmias. N Engl J Med 345: 1473-1482. [Crossref]

6. Das MK, Khan B, Jacob S, Kumar A, Mahenthiran J (2006) Significance of a fragmented QRS complex versus a Q wave in patients with coronary artery disease. Circulation 113: 2495-2501. [Crossref]
7. Peters S, Trummel M, Koehler B (2008) QRS fragmentation in standard ECG as a diagnostic marker of arrhythmogenic right ventricular dysplasia-cardiomyopathy. Heart Rhythm 5: 1417-1421. [Crossref]

8. Morita H, Kusano KF, Miura D, Nagase S, Nakamura K, et al. (2008) Fragmented QRS as a marker of conduction abnormality and a predictor of prognosis of Brugada syndrome. Circulation 118: 1697-1704. [Crossref]

9. Flowers NC, Horan LG, Thomas JR, Tolleson WJ (1969) The anatomic basis for highfrequency components in the electrocardiogram. Circulation 39: 531-539. [Crossref]

10. Friedman PL, Fenoglio JJ, WitAL(1975) Time course for reversal of electrophysiological and ultrastructural abnormalities in subendocardial Purkinje fibers surviving extensive myocardial infarction in dogs. Circ Res 36: 127-144. [Crossref]

11. Gardner PI, Ursell PC, Fenoglio JJ Jr, Wit AL (1985) Electrophysiologic and anatomic basis for fractionated electrograms recorded from healed myocardial infarcts. Circulation 72: 596-611. [Crossref]

12. Das MK, Khan B, Jacob S, Kumar A, Mahenthiran J (2006) Significance of a fragmented QRS complex versus a $Q$ wave in patients with coronary artery disease. Circulation 113 : 2495-2501. [Crossref]

13. Das MK, Suradi H, Maskoun W, Michael MA, Shen C, et al. (2008) Fragmented wide QRS on a 12-lead ECG: a sign of myocardial scar and poor prognosis. Circ Arrhythm Electrophysiol 1: 258-268. [Crossref]

14. Das MK, Saha C, El Masry H, Peng J, Dandamudi G, et al. (2007) Fragmented QRS on a 12-lead ECG: a predictor of mortality and cardiac events in patients with coronary artery disease. Heart Rhythm 4: 1385-1392. [Crossref]

15. Pietrasik G, Goldenberg I, Zdzienicka J, Moss AJ, Zareba W (2007) Prognostic significance of fragmented QRS complex for predicting the risk of recurrent cardiac events in patients with Q-wave myocardial infarction. Am J Cardiol 100: 583-586. [Crossref]

16. Kadi H, Ceyhan K, Koç F, Celik A, Onalan O (2011) Relation between fragmented QRS and collateral circulation in patients with chronic total occlusion without prior myocardial infarction. Anadolu Kardiyol Derg 11: 300-304. [Crossref]

17. Brenyo A, Pietrasik G, Barsheshet A, Huang DT, Polonsky B, et al. (2012) QRS fragmentation and the risk of sudden cardiac death in MADIT II. $J$ Cardiovasc Electrophysiol 23: 1343-1348. [Crossref]

18. Tigen K, Karaahmet T, Gurel E, Cevik C, Nugent K, et al. (2009) The utility of fragmented QRS complexes to predict significant intraventricular dyssynchrony in nonischemic dilated cardiomyopathy patients with a narrow QRS interval. Can J Cardiol 25: 517-522. [Crossref]

19. Cheema A, Khalid A, Wimmer A, Bartone C, Chow T, et al. (2010) Fragmented QRS and mortality risk in patients with left ventricular dysfunction. Circ Arrhythm Electrophysiol 3: 339-344. [Crossref]

20. Forleo GB, Della Rocca DG, Papavasileiou LP, Panattoni G, Sergi D, et al. (2011) Predictive value of fragmented QRS in primary prevention implantable cardioverter defibrillator recipients with left ventricular dysfunction. J Cardiovasc Med 12: 779784. [Crossref]

21. Cetin M, Kocaman SA, Erdogan T, Durakoglugil ME, Cicek Y, Bozok S, et al. (2012) Fragmented QRS may predict postoperative atrial fibrillation in patients undergoing isolated coronary artery bypass graft surgery. Anadolu Kardiyol Derg 12: 576-583. [Crossref]

22. Temiz A, Gazi E, Güngör O, Altun B, Barutcu A, et al. (2014) Fragmented QRS and prediction of paroxysmal atrial fibrillation episodes. Pak J Med Sci 30: 862-867. [Crossref]

Copyright: (C2018 Centurión OA. This is an open-access article distributed under the terms of the Creative Commons Attribution License, which permits unrestricted use, distribution, and reproduction in any medium, provided the original author and source are credited. 